Scientił studia, São Paulo, v. 8, n. 2, p. 293-8, 2010

\title{
st \\ O conhecimento na física: do invisível segundo a observação ao visível segundo o pensamento
}

Michel PATY

1 A física contemporânea (aquela que começou no início do século xx) é, de certo modo, uma física do invisível, de um invisível que era até então dado como quase certamente incognoscível: os átomos e todos os fenômenos do domínio atômico e subatômico. De fato, a física fez esse invisível tornar-se cognoscível, desenvolvendo para isso instrumentos materiais (aparelhagens) e intelectuais (conceitos, modelos teóricos e teorias). Ainda melhor, ela fez esse invisível tornar-se visivel.

2 Existe uma diferença entre o cognoscível e o visível, a saber, o cognoscível pode ser conhecido indiretamente por uma teoria e por experiências, mas elas certamente não nos trariam, senão de longe e de maneira mediata, as informações (que podem ser exatas) sobre o domínio invisível. Tal é, por exemplo, o estatuto do domínio quântico tal como o concebia a teoria quântica na perspectiva da Escola de Copenhague. A "teoria quântica" não seria, com efeito, senão um formalismo matemático sobre quantidades abstratas, sem contraparte física direta, aumentada por uma "interpretação". Esse formalismo é o da função de estado definida sobre um espaço matemático abstrato de Hilbert - ou amplitude de probabilidade - e dos operadores hermíticos que agem sobre essas funções, correspondendo a "observáveis" dos quais, entretanto, somente os "valores próprios" são observados etc. A interpretação, indissociavelmente física e filosófica segundo o pensamento "ortodoxo" da Escola de Copenhague, estabelece a relação entre essas entidades abstratas do formalismo e os resultados da observação e da experiência.

Algumas dessas interpretações são simplesmente regras (aceitas por todos) que dão o sentido físico das grandezas, tal como a interpretação probabilística da função de estado de Max Born (que a fixa como amplitude de probabilidade); ou como a complementaridade das grandezas clássicas para descrever os sistemas quânticos, a qual estabelece em qual medida as grandezas clássicas podem ainda descrever os sistemas 
quânticos, dado que elas são por si mesmas insuficientes; estritamente falando, a complementaridade concerne às propriedades mútuas de grandezas quânticas incompatíveis (cujos operadores não se comutam entre si). Elas são resumidas, enquanto grandezas (operadores) quânticas, pelas relações de anticomutação e, enquanto grandezas na aproximação clássica, pelas desigualdades de Heisenberg.

Outros são enunciados filosóficos sobre o conhecimento. Descrever os sistemas quânticos não tem sentido independentemente de suas condições de observação; não se pode descrever um sistema isolado, mas somente um sistema inseparavelmente ligado ao instrumento (clássico) de sua observação... Em resumo, segundo a interpretação dominante na época pioneira da mecânica quântica, não se pode pensar os sistemas quânticos de maneira intrínseca, uma vez que esse pensamento é em si mesmo sempre condicionado pelo modo clássico de pensar, o qual está associado aos meios de observação (sempre por meio de aparelhagens clássicas).

3 Poder-se-ia, entretanto, objetar a isso que o conhecimento não se fundamenta somente na observação, mas também no raciocínio e que o poder de representação do pensamento pode, se certas condições forem dadas, antecipar as possibilidades de observação. Assim, é desta maneira que a teoria física funciona frequentemente, a predição teórica de um fenômeno precede na maioria das vezes suas condições experimentais (por exemplo, a predição das ondas eletromagnéticas pela teoria de Maxwell e, em particular, que a luz é uma onda eletromagnética em um certo domínio de comprimento de onda). Retenhamos desse estado de coisas que o pensamento teórico constitui o verdadeiro meio intelectual que nos auxilia a representar os fenômenos e as realidades do mundo físico e de compreendê-los. A observação tem um papel fundamental, na via ascendente (ela permite formar as condições dessa representação) e na via descendente (ela constata, verifica e precisa aquilo que o pensamento teórico procura ligar e explicar em seu sistema simbólico).

4. Entretanto, a física deu, no século xx, um passo a mais ao fazer que esse cognoscível (ver §2) torne-se visível, de maneira a entendê-lo no sentido de conhecido diretamente. Precisemos o que devemos entender por isso. Pode-se compreendê-lo no sentido literal, inicialmente (ainda que não se trate do "visível" no sentido do que é aclarado pela luz visível: mas, agora, os raios $\mathrm{X}$, e todos os tipos de irradiação, compreendidos os neutrinos e logo, sem dúvida, os grávitons, sem esquecer dos aceleradores de partículas quânticos, que permitiram ampliar consideravelmente o sentido antigo de "visível"). Falando literalmente, a experiência nos faz ver, desde um ou dois decênios, os átomos individuais. Ela nos permite ver os sistemas quânticos agregados (quantons) idênticos que alcançam as dimensões macroscópicas de um volume visível no espaço, 
tais como os condensados de Bose-Einstein, observados pelo microscópio. Ela nos faz ver os estados quânticos intrincados (entangled) (gatos de Schrödinger mesoscópicos) e a própria transição pela qual eles passam do estado intrincado (coerência quântica) ao estado desintrincado (decoerência).

5 Ao mesmo tempo, a teoria quântica é "interpretada" de fato, quando é posta em operação na física (independentemente de qualquer consideração filosófica explícita), distintamente da maneira pela qual tínhamos acreditado poder considerá-la na etapa pioneira precedente. Ela não tem mais necessidade de ser interpretada do exterior, ela fornece ela mesma, com suas próprias fontes, desde o interior, os elementos fundamentais de sua interpretação. A física quântica contemporânea concebe de fato que a teoria apresenta uma representação direta dos sistemas e dos fenômenos quânticos, tal como eles são supostos serem ou produzirem-se em seu nível, sem referência ao nível macroscópico clássico. (Ela o concebe pelo menos implicitamente, ela o faz como se esse fosse realmente o caso.)

Areferência da descrição e da compreensão dos sistemas e fenômenos quânticos não é, de modo algum, a observação e seus condicionamentos macroscópicos e clássicos, mas aquilo que existe ou que acontece no próprio nível quântico. Isso é devido a que os físicos pensam atualmente os sistemas quânticos através da teoria quântica, que se tornou inteligível, apesar de suas obscuridades iniciais. Por esse exercício prático e constante de seu pensamento teórico, que consiste em conceber as grandezas segundo sua forma matemática, dada pelo "formalismo", tendo em vista que é assim que temos acesso às propriedades especificamente quânticas (considerando especialmente a importância para isso do princípio de superposição), podemos mudar o sentido inicial desse formalismo para aquele da teoria física propriamente falando; de fato, esses elementos do formalismo ficam carregados de conteúdo físico em virtude dessa própria operação, sistematicamente repetida e realizada.

Os físicos integraram ao seu modo de pensar, como conceitos físicos e como relações de conceitos (e, portanto, como teoria física no sentido próprio), o instrumento, inicialmente concebido como neutro em relação aos sentidos, aos conteúdos dos sentidos (quanto à física), que era o formalismo teórico no período inicial, isto é, a forma matemática das grandezas. De fato, essas grandezas são hoje em dia pensadas como conceitos físicos, portadores de conteúdos físicos, repletos de fenômenos.

6 Nessa visão, o pensamento teórico concebe e caracteriza os sistemas quânticos (é a eles que ele se refere), depois sujeita-os à prova da experiência por intermédio de aparelhos, certamente clássicos em última instância, mas cujo agenciamento está organizado em vista das relações de propriedades quânticas ditadas pela teoria; em seguida, os resul- 
tados da experiência (em geral, de natureza estatística) são relacionados às características teóricas (não clássicas!) dos sistemas quânticos, dos quais teremos, assim, esclarecido as propriedades. Em suma, a experiência não nos terá feito sair do pensamento do sistema quântico. E pode-se até mesmo dizer que é ela, a experiência, pelo caráter clássico de suas aparelhagens, que é indireta para os sistemas quânticos em exame, não a representação teórica quântica, a qual é direta no sentido indicado e justificado.

7 Resulta disso uma mudança de perspectiva em relação à primeira maneira de ver. A caracterização do domínio quântico dependia da abordagem que era possível pela física clássica. O mundo quântico é hoje em dia conhecido como subjacente ao mundo macroscópico clássico, de maneira objetiva, de tal modo que o mundo macroscópico emerge ou resulta da organização do mundo quântico subjacente. Pelo menos é assim que se concebe as coisas hoje em dia, senão ainda filosoficamente, pelo menos na maneira de praticar e de conceber a física, clássica e quântica.

8 Entretanto, nem tudo é exatamente claro. Pois permanecem em certos lugares obscuridades quanto ao conhecimento e a compreensão que temos da interface entre o mundo quântico e o mundo clássico. Os dois domínios são bem caracterizados e de maneira independente entre si. Temos um conhecimento preciso do mundo quântico, pela teoria quântica, que nos torna esse mundo "visível". Temos um conhecimento preciso do mundo macroscópico, pelas teorias clássicas e relativistas. Mas não dispomos da ligação entre os dois. Os conceitos quânticos podem dar conta dos conceitos clássicos? Não parece, a menos que proponhamos um dia uma reconstrução explícita. Cada um dos níveis, quântico e clássico-macroscópico, é caracterizado pelo seu sistema teórico-conceitual; os dois sistemas resultam de tipos de abordagens diferentes, cada abordagem inscrita em uma duração e em um contexto histórico próprios.

A teoria da decoerência ilustra isso muito bem no que lhe concerne, ao mostrar como os caracteres quânticos dissipam-se nas condições de interação e de intrincamento múltiplas entre sistemas quânticos nos meios materiais, e não se encontram nos sistemas de corpos numa escala maior. Mas isso nada diz sobre a maneira pela qual as propriedades físicas clássicas aparecem nesse nível mais elevado de organização da matéria, para o qual contentamo-nos em retomar os conceitos clássicos.

9 Por exemplo, como o espaço no sentido físico clássico (representado por um contínuo de pontos) engendra, a partir da agregação a uma escala relativamente grande, os sistemas físicos quânticos? Com efeito, sabemos que o conceito de espaço não é intrínseco à teoria quântica e até mesmo que ele é, sem dúvida, estranho a ela, se se pensar na não separabilidade, na indiscernibilidade das partículas ou dos sistemas quân- 
ticos idênticos, em suas definições e em suas consequências etc. Contudo, os corpos macroscópicos, que são grandes agregados de sistemas quânticos, não podem ser pensados sem o conceito de espaço. As próprias partículas quânticas deslocam-se no espaço - sendo verdade que, em tal caso, trata-se de um meio que lhes é exterior, mas que é ele mesmo o resultado da cosmogênese. Esse meio, o espaço, é bem conhecido pela teoria da relatividade geral, de maneira que a dinâmica do universo é aquela do campo clássico (por oposição ao quântico, mas de fato relativista) de gravitação, e sua métrica para todo ponto do espaço-tempo é determinada pelos campos de gravitação engendrados pelas massas que eles contêm. Mas quando e em quais condições esse campo métrico se move de lugar? Que sabemos sobre o período intermediário ou de transição, nos limites do início do período cosmológico precoce, quando esse campo toma forma e se determina, quando as condições quânticas do universo primordial começam a não mais prevalecer e a matéria e a radiação se desatrelam?

Não podemos pensar que as dificuldades do "modelo standard" da cosmologia estão ligadas a essa fase, antes que, talvez, aos fenômenos que exigem hipóteses suplementares muito particulares?

10 Pela ordem dessas observações, e não por outra razão, nesta intervenção, os “invisíveis" da cosmologia são tratados apenas da perspectiva daqueles da física quântica. Direi apenas de passagem aqui que a reflexão sobre os invisíveis do mundo microscópico-quântico não lhe é, sem dúvida, estranha. Isto, em primeiro lugar, por uma razão geral, que é a mesma da qual falamos inicialmente, a saber, a progressão do conhecimento que vai do visível segundo os sentidos ao visível segundo o entendimento. Em segundo, por aquela razão que é própria da cosmologia evolucionária, de que as grandes estruturas do universo estão relacionadas à organização da matéria em seu nível mais tênue, em seus inícios segundo a escala do tempo cosmológico e, portanto, que as condições do conhecimento, que são apropriadas para cada um dos dois domínios, convergem ou imbricam-se. A física simplifica essa enorme complexidade, ao fazer da cosmologia uma de suas províncias: ela toma por objeto não simplesmente uma parte da matéria, mas a matéria do universo inteiro, e ela parece sentir-se aí à vontade. Seu imenso sucesso não dissipou todas as sombras, talvez porque ela não tenha um instrumento único para ver esses dois objetos que, no fim das contas, se superpõem. Ela deve contentar-se ainda com uma dualidade prática do ponto de vista de seus conceitos. Sua visão do universo único não está ainda bem costurada... 
Esta nota resulta de uma comunicação na mesa redonda "Invisible, inexpliqué ou inintelligible", no Colóquio "L'univers invisible. Energie noire, matière noire: l'univers outre-noir", ocorrido no Palácio da Unesco, em Paris, no dia 10/jul./2009.

Traduzido do original em francês por Pablo Rubén Mariconda e Claudemir Roque Tossato.

\section{Michel PATY}

Diretor de pesquisa emérito do Centre National de la Recherche Scientifique. Equipe REHSEIS, Universidade de Paris 7, França. michel.paty@univ-paris-diderot.fr

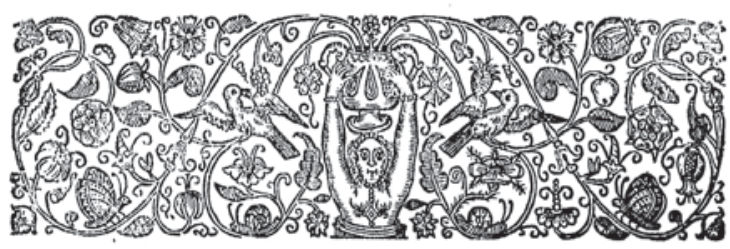

